Proceedings of the 2011 Winter Simulation Conference

S. Jain, R.R. Creasey, J. Himmelspach, K.P. White, and M. Fu, eds.

\title{
ON INNOVATION, AND BUILDING AND SUSTAINING A SUCCESSFUL CAREER IN RESEARCH
}

\author{
Richard M. Fujimoto \\ School of Computational Science and Engineering \\ Georgia Institute of Technology \\ Atlanta, Georgia 30332
}

\begin{abstract}
Innovation and the generation of new knowledge are fundamental research goals. As such, proficiency in these areas is essential to becoming a successful researcher. Yet, although a principal goal of graduate school is to train students to become effective researchers, innovation is seldom explicitly discussed. The goal of this article is to fill this gap. Specifically, I provide some insights into the process of innovation and suggest activities that may help to increase one's capacity for innovative thought, and ultimately, help build a successful, sustained career in research.
\end{abstract}

\section{INNOVATION}

Most graduate programs, quite correctly, focus their attention on developing deep technical expertise in a subject area. To be sure, technical excellence is essential. However, technical excellence tells only part of the story in building a successful career in research. A number of other aspects are as important, and in some cases, perhaps even more important to achieving sustained success. It is often the case that these other aspects remain unsaid, and are not taught in university classes or graduate research programs. More often than not these are things that are only learned through experience, and sometimes through painful mistakes.

It has become widely accepted that innovation is a key ingredient to success, from a global and national level, down to the individual. It has been well understood for some time that innovation directly impacts the economic success of nations. For example, innovation was highlighted by U.S. President Barack Obama in his 2011 State of the Union address, where he cited developments such as computers, the Internet, automobiles and aircraft, as examples of inventions that spawned major new industries, and changed the way we live (Obama 2011). Major companies have succeeded because of their ability to innovate, while others have failed because they could not, e.g., see (Lafley and Charan 2008).

Innovation, of course, starts with the individual. One's ability to create, nurture, and sustain innovation can make or break one's career. It is hard to imagine a job where developing new ideas to streamline or improve the way things are done will not separate one from other employees or competitors, and greatly enhance one's chances of success. There are few professions where innovation is more fundamental to a business than in research, the very nature of which is concerned with the creation of new theories, knowledge, ideas, artifacts, methodologies and techniques. It is clear that to be a successful researcher, one must innovate.

A principal purpose of graduate school, and doctoral programs in particular, is to train individuals for a career in research. Yet, few doctoral programs in science, engineering, and computing explicitly focus attention on innovation, or discuss how innovation happens or what one should do to become a more innovative researcher. At best, an implicit, "learn by doing" approach is used where students are somehow expected to pick up on their own how to be innovative. Speaking from personal experience, this was the 


\section{Fujimoto}

case in my own professional career including undergraduate and doctoral studies as well as rising through the professorial ranks at several major universities in the United States.

Innovation is the central topic of this article. This article was written from the perspective of someone engaged in research in academic environments over the last 30+ years. While I did not explicitly study innovation as a topic in its own right throughout much of my academic career, this changed in 2005 when I took on an administrative position as the chair of a new department. While I recognize that there are no cookbook recipes for creating innovation, there are things one can do to structure one's environment and one's career to foster the creation of new ideas. This article attempts to summarize some of these ideas with the hope it might motivate other researchers, particularly those just completing their doctoral studies, to consider how they can better position their lives and careers in a way to sharpen and develop their ability to innovate.

\section{WHAT DO THE PRINTING PRESS, INFANT INCUBATORS, AND FRISBEES HAVE IN COMMON?}

Around the year 1440, a German named Johannes Gutenberg, a goldsmith by trade, combined and adapted a number of existing technologies of the day to develop the world's first movable type printing press. His invention utilized technologies such as the screw-type wine press that had been used to make wine, movable type that had also been around for some time, and innovations of his own such as a mould for creating type. His invention enabled high quality documents to be created far more inexpensively than was previously possible. The movable type printing press is credited with helping to launch the Renaissance period in Europe, and ultimately changed the world.

Over four centuries later, an obstetrician named Stephane Tarnier in Paris visited the zoo. An exhibit of chicken incubators triggered an idea, and the hiring of a zoo employee that resulted in the creation of an incubator adapted for human babies. He immediately began to utilize it in the maternity ward of the hospital in which he worked. The results of this invention were stunning. Statistics from a quantitative experiment he conducted shortly after the installation of the incubator showed that mortality rates among low-weight babies were nearly halved. Modern incubators in the U.S. are credited with a $75 \%$ reduction in infant mortality rates from 1950 to 1998 (Johnson 2010).

It is not clear who first had the idea of making a game of "catch" by flinging empty bakery pie pans, however, Walter Morrison is credited with commercializing the idea. He reports the initial idea of creating a business around "flying disks" came to him in 1938 on a California beach. Twenty years later he developed a version that was marketed by the Wham-O company and patented in 1958 under the name "frisbee," named after the Frisbie pie making company in New England (Morrison and Kennedy 2006). Today, there are few people who are not familiar with the frisbee. The World Flying Disc Federation is an international organization that manages rules, standards, and events associated with sports based on the frisbee (World Flying Disc Federation 2011).

The point of these stories is to highlight that innovation seldom comes about by new ideas spontaneously "appearing" in a vacuum. Rather innovation often comes about by adapting and applying existing ideas or technologies for another purpose. Often, the most striking innovations come about by taking concepts and techniques known in one field, and adapting them to another. This is certainly the case in the three examples cited above. Many of the parts of the movable type printing press reused existing technologies in unrelated industries and disciplines. Similarly, the incubator and Frisbee both involved transplanting technologies from one field to another. History is full of examples such as these. It is usually the case that the inventors of the original concept never conceived of applying their innovation for these entirely new uses.

Steven Johnson eloquently characterizes this phenomena as a concept called the adjacent possible that he borrowed from evolutionary biology. Evolutionary biology is a field that is concerned with the origins and evolution of life. How did the vast richness of life that exists today evolve from the primordial soup of organic molecules and compounds? An elephant does not immediately emerge from a random collection of methane and oxygen molecules. Rather, it is a long sequence of molecules colliding with 


\section{Fujimoto}

other molecules, and the resulting structure combining with other structures to create progressively more complex organisms over billions of years of evolution. Stuart Kauffman coined the term the adjacent possible to characterize the next generation of evolutionary innovation that could result by a new combination of molecular interactions that are possible from those that previously existed. As Johnson writes, "the adjacent possible is a kind of shadow future, hovering on the edges of the present state of things, a map of all the ways in which the present can reinvent itself." The space of possible new combinations is vast, but it is not infinite. The adjacent possible provides a way of characterizing not only what new combinations might be created, but also what combinations cannot, or at least are exceedingly unlikely to form. While creating basic sugar or protein molecules from the primordial soup may be possible, creating an elephant all in one step is not.

The adjacent possible is a useful concept to characterize the process of innovation - how one idea leads to another, and another, leading to increasing sophistication and complexity. Just as some evolutionary branches prove to be unproductive and wither away and die, while others flourish and become spectacularly successful, so too is it with innovation. Johnson views the world as essentially a large collection of "spare parts," and innovation comes about through the combination of these spare parts in novel ways for new purposes. Just as nature "innovates" by combining molecules and systems in new ways, good ideas come about from the connection of ideas and concepts. Just as organisms accumulate complexity as one new form builds upon another, innovations build upon each other to create an ever increasing supply of spare parts that can be reapplied for still other purposes.

Characterizing the process of innovation in terms of the adjacent possible concept is useful because it provides some insight into how innovation takes place. When viewed in this light, it suggests that to be innovative, one should build a large collection of spare parts and establish networks that enable these spare parts to combine in novel ways. This is the basic premise from which I wish to depart for the remainder of this article.

\section{FROM SHORT AND FAT, TO TALL AND THIN, TO T-SHAPED PEOPLE}

Assuming one subscribes to the theory of the adjacent possible, the first question that comes to mind is what sorts of spare parts should one collect? This hits directly on the question of what should be included in the curriculum for a discipline? There has long been much discussion, and a certain amount of concern, that university curricula may be becoming overly specialized. In other words, programs run the danger of becoming very good at producing individuals with very deep knowledge and expertise in one subject area, but limited exposure to others, even others that may be closely aligned with the student's major area of study. To some extent, overspecialization reflects a natural evolution and maturing of a discipline. As new advances expand the body of knowledge in a field, it is natural for faculty to continually incorporate more and more of this new knowledge in their curriculum, while being reluctant to drop topics that have long been an established part. "How can someone be considered an expert in X without knowing about Y?" could often be heard at university curriculum committee meetings.

In one area, integrated circuit design in the 1970's, this concept was represented by what Carver Mead referred to as the "short, fat man" (Glider 1989). Mead was one of the leaders of the then exploding field of microelectronics and circuit design that in the 1970's was resulting in the first microprocessors that would soon revolutionize the computing industry. The short fat man was an icon for an individual who has deep knowledge and expertise in one aspect of integrated circuit design, for example, chip layout and fabrication or electronic circuit design (see Figure 1). By contrast, Mead argued for creating the "tall, thin man," i.e., someone with knowledge spanning many areas ranging from fabrication and layout to circuit design, to logic and computer arithmetic to systems architecture to system software, compilers, languages, and even computer applications. It was argued that the explosion in complexity resulting from Moore's law which predicted an exponentially increasing number of transistors that could be placed on a silicon die over time, necessitated the creation of individuals who could peer across the different areas, and develop new approaches that would be needed to dramatically reduce the time required to design new chips. Silicon "compilers" were one result of this methodology that borrowed ideas from software com- 


\section{Fujimoto}

pilers, and applied them to circuit design where chips were designed at higher levels of abstraction, and automatically "compiled" to circuits, dramatically reducing the time required to design new chips. A "tall thin man" was needed to create such design systems. The concept of the "tall thin man" is, of course, not new; he is one variant of the "renaissance man" commonly known to as a well-educated individual who has broad expertise spanning many different subject areas.

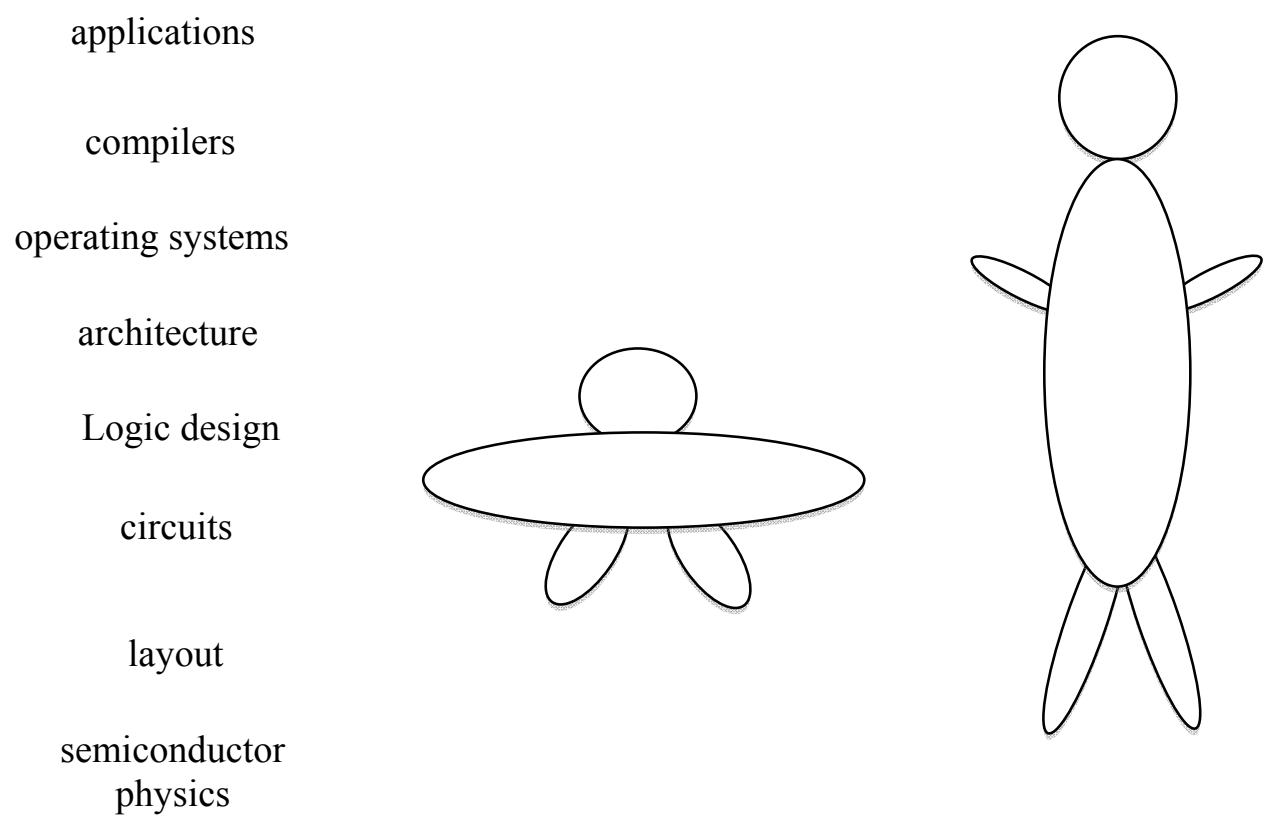

Figure 1: the short, fat man has deep expertise in one field; the tall, thin man has broad expertise across many areas, but not deep expertise in any one

While the short, fat man offers the ability to innovate deeply within a knowledge area by refining and continuing development of a concept or idea, this profile does not lend itself to the cross-fertilization and transplanting of ideas across disciplines, a key skill in fostering innovation. Rather, diverse ideas were needed to create inventions such as the printing press. As such, the tall, thin and renaissance man seems much better suited for this cross-pollination of ideas that can result in novel combinations that have not been seen before.

However, the tall, thin man runs the risk of being too general - possessing superficial knowledge in many things, but lacking deep knowledge and expertise within a particular discipline. Therefore, rather than recommending either of these profiles, I advocate the T-shaped woman, borrowing a name coined in (Kelley and Littman 2005). The T-shaped woman (see Figure 2; note the axes have been transposed), possesses deep understanding and expertise within one discipline or field, but literacy and understanding across many aligned or related disciplines. The T-shaped woman possesses sufficient understanding to know how to apply principles and insights within one domain to find application in another.

The modeling and simulation (M\&S) field is particularly well-suited for developing T-shaped people. To become an M\&S expert, one must develop deep expertise in areas such as modeling methodology and analysis techniques, while also requiring one to dive into one or more application domains to understand how the technology can be applied. As such, M\&S professionals are very well suited to understand how ideas in one domain may find application in others, and I would argue can be well positioned to creating a profile that is very well suited for innovation. 


\section{Fujimoto}

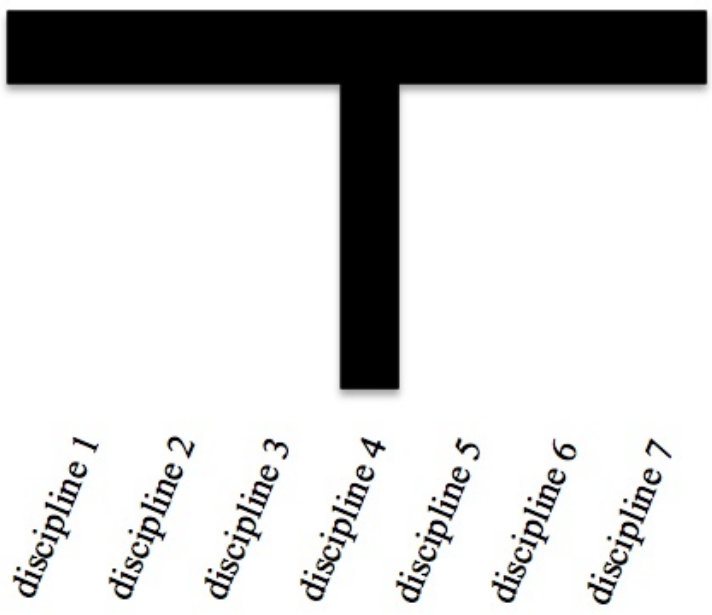

Figure 2: the T-shaped woman has broad expertise in many areas and deep expertise in one

\section{A GUIDE TO INNOVATION TRAINING}

If the T-shape individual is the preferred profile for fostering the collision and transplanting of ideas that result in innovation, how does one go about establishing such a profile? Just as diet and exercise provide the tools for shaping the human physique, these two elements play a key role to building one's T-shape intellect. Here, the "diet" consists of ideas and concepts, and "exercise" means what one does to establish networks where these ideas and concepts can collide to create new ones. In the following I provide a number of suggestions aimed at improving one's diet and exercise to prepare oneself for innovation. To be clear, there is no "cookbook recipe" that will result in innovation. The following are only suggestions that may help facilitate innovative thought. It should be emphasized that developing a T-shaped profile is not something restricted to one's formal education. Rather, this is a lifelong activity that must continue throughout one's entire career.

\section{Suggestion 1: Find time to expose one's self to new fields.}

It is easy to let deadlines and deliverables and day-to-day activities fill one's day. And when there is time to deepen one's knowledge, one's immediate inclination is to focus on developing the vertical part of the ' $\mathrm{T}$ ', i.e., deepening expertise in the area in which one already has the greatest knowledge. While no one will argue that it is important to keep up in one's own field, often this leaves little time to explore other areas and disciplines, especially those that are rather distant from one's own field. Nevertheless, as was discussed earlier, it is insights and observations within another field that can lead to the greatest innovation in one's own discipline. One way to broaden one's perspective without consuming an inordinate amount of time is through seminars and spending time to talk to visitors that come through one's workplace.

Another approach is to read broadly outside one's own discipline. Carving off specific time periods or utilizing audiobooks for the daily commute to and from work are great ways to ensure one gets a steady diet of new materials. Evaluate what you read to determine if it is having the desired effect. Make note of interesting concepts and store them away for future reference. Brainstorming sessions with individuals from another discipline, is another useful technique to gain new insights (Kelly and Littman 2001).

The web is a tremendous asset that can accelerate innovation by putting knowledge on virtually any subject at one's fingertips, instantly. The trick, of course, is to structure your use of the web to filter in- 


\section{Fujimoto}

formation, so the right ideas connect at the right time, to create that innovative spark. Inspirational talks, such as the TED series, are a good source of new ideas (TED: Ideas Worth Spreading 2011).

\section{Suggestion 2: Join a multidisciplinary research team.}

Multidisciplinary research projects provide a way to maintain sustained interactive dialogs with persons from other disciplines. Multidisciplinary research has become popular in recent years for pragmatic reasons. Many of the most important problems facing the world today, such as establishing clean, abundant sources of energy, creating sustainable cities, or developing and delivering cures and treatments for disease on a global scale, cannot be solved by individuals from one discipline alone. While this is true and is the main reason multidisciplinary research has increased in recent years, our interest in creating teams of individuals from different disciplines lies in providing a critical vehicle for connecting diverse ideas in order to increase innovation.

Of course, joining and contributing to a multidisciplinary team is not a trivial matter. A significant effort is required to be able to engage with individuals from another field, and achieve the deep levels of interaction necessary to produce the "collision of ideas" that can spark new innovation. Different disciplines use entirely different vocabularies. There are underlying assumptions and principles that are often implicit and unsaid (and sometimes not even recognized) by persons within a discipline, that may be entirely unknown to immigrants. Thus a key step is to be able to communicate within the multidisciplinary team. One must first be able to express concepts from one's native discipline in terms that can be understood by others in another. The next step is to be able to absorb concepts from another discipline. The final step, which is where innovation comes in, is to transplant concepts from another discipline in order to alter the research one does in their native discipline, or in some cases, to create concepts for a new discipline that lies at the intersection between the two. The empty space that lies at the seams between existing disciplines is often the most fertile ground for new ideas and innovation.

To this advice, I add one word of warning, especially for new junior faculty. Traditional promotion and tenure processes are not always proficient at recognizing and rewarding contributions to multidisciplinary research, and often rely on metrics geared toward contributions within one's own native discipline. Some would argue there is good reason for this, pointing to the need to develop the vertical portion of one's ' $\mathrm{T}$ ' before broadening your base of expertise. To this I would argue that exploring another discipline can strengthen one's ability to innovate in one's own discipline. A good example of this is the field of biologically inspired design, that borrows ideas of how biological systems adapt and evolve in nature, to create more robust and effective man-made systems. This approach has resulted in entirely new approaches in areas such as robotics and computer network security.

\section{Suggestion 3: Get out of your office or cubicle.}

The French mathematician Henri Poincaré described how a difficult problem on which he had been struggling for some time was suddenly solved one day, during a walk at the seaside (Poincaré 1913). Similarly, Karl Frederick Gauss reported that, after struggling with a difficult theorem for two years, "Finally, two days ago, I succeeded - not on account of my hard efforts, but by the grace of the Lord. Like a sudden flash of lightning, the riddle was solved. I am unable to say what was the conducting thread that connected what I previously knew, with what made my success possible" (Eves 1972).

It is often the case that breakthrough ideas come not while one is sitting at a desk consciously trying to solve a tough problem, but rather, when one steps back, works on other problems, or engages in unrelated activities such as going for a walk or taking a shower. A coffee shop is another useful venue that may help coax the creation of new ideas. Repetitive actions such as taking a jog or a shower can allow connections to form in the brain that might not otherwise occur, leading to new insights that are less likely to occur when consciously seeking a solution. There is something to be said for taking a break to clear one's mind of minute details of the problem at hand, and to allow new thoughts to bubble up from one's 


\section{Fujimoto}

subconscious. So my advice here is simple. If you are stuck on a tough problem, find a place outside your usual workplace where you can step back and think about it in a different environment.

Suggestion 4: Know what you are good at; make sure you can do it, every day.

The rationale for this advice is obvious. If you focus on the things you are good at, you are most likely to maximize your potential and success. Most likely, you enjoy doing the things you are good at, and so are likely to find job satisfaction as well. Of course the problem is the second part - ensuring you can do what you enjoy and are good at every day. It is easy to get bogged down in deadlines, day-to-day activities and the like that can keep one from doing what one really enjoys. My advice is to be sure to set aside some time, ideally every day, to pursue the things that you are passionate about. Academic careers usually offer sufficient flexibility to do this. But even in industry, enlightened companies are increasingly allowing employees to set aside time in this way. $3 \mathrm{M}$ was one of the first major corporations to explicitly embrace innovation as a corporate strategy. Credited with inventions such as Post-It notes and scotch and masking tape, $3 \mathrm{M}$ allowed employees to spend $15 \%$ of their time to explore projects of their own choosing. More recently, Google has adopted a similar policy by allowing employees to spend $20 \%$ of their time for the same. Much innovation has resulted from this rule.

Perhaps more problematic, especially for those early in their careers without the benefit of a wealth of experience, is knowing what one is good at. Knowing one's self is harder than one might initially think. The basic problem is how do I know if I am good at something, or enjoy it, until I've tried? As such, experimentation is often needed, which leads to my next suggestion.

\section{Suggestion 5: Fail fast and be persistent.}

Thomas Edison, one of the greatest inventors in American history was known for his persistence and passion for experimentation. He once remarked about his work on the light bulb "I have not failed. I have merely found ten thousand ways that won't work." Companies have long known the benefits of rapid prototyping, i.e., to try out and experiment with ideas to gain a feel for whether they are viable and practical before expending the time and resources in developing a more elaborate prototype. The same applies in many other areas as well. Don't be afraid to try new things and ideas, and don't be afraid to fail. Just make sure you learn from your failures, and don't invest too much time to figure out if a new idea has promise.

Sometimes, being persistent requires one to bend the rules of corporate (or academic) bureaucracy. An example of this is related in Kelley and Littman (2005) in describing the invention of masking tape by Richard Drew at 3M in the 1920's. At the time, 3M's business was in designing and manufacturing sandpaper. In delivering a batch of sandpaper to an automobile body shop in St. Paul, Minnesota, Drew discovered that an area of great frustration at the body shop was in two-tone paint jobs for vehicles, which had become very popular at the time. Drew realized that by creating an adhesive tape to mask areas that were not to receive paint, this problem could be addressed. Armed with this knowledge, he set out to invent what we now know as masking tape, specifically to address this need. The president of $3 \mathrm{M}$ company was not sympathetic to this effort, however, and when Drew asked for funds to purchase a tape making machine to create prototypes of his creation, the company refused. Drew persisted. He was authorized to make purchases of up to $\$ 100$ without obtaining additional approvals. He then set forth to issue a series of $\$ 99$ purchase orders to pay for the machine, and produced the world's first masking tape. In subsequent

years, Drew went on to create other innovations, such as his invention of a clear cellophane version of masking tape that we now know as scotch tape. 


\section{Fujimoto}

\section{Suggestion 6: Find ways around your weaknesses.}

No one is good at everything. The corollary to knowing what you are good at is to understand those things for which you are not, and to find ways to work around them. An obvious work around is simply to find training to become competent in the area, though if you are not very good at it to start with, chances are you will never excel in that area. In some cases technology can help. For example, if you are not very good at time management, there are software tools that can help you better manage your time. Another approach is to find one or more partners who are excellent in the areas where you are weak, and work with them so each of you can leverage each other's strengths. If your artistic talents are weak but needed for a project, find someone who is gifted in this area. This is particularly useful as you become more senior in your career, and are able to hire staff to work with you on projects.

\section{Suggestion 7: Work on problems that matter. Think big.}

It is not a coincidence that important people tend to work on important problems, i.e., problems that matter. How do you know if you are you working on an important problem? A good litmus test is to ask the question: if you succeed, who will care? Is the answer just you? your immediate research group? your sub-discipline within the field? the broader research community? society at large? Will your research be important enough that national media outlets would be interested in reporting your results?

In his description of the events leading to the discovery of the structure of DNA, James Watson explains how his previous lack of interest in chemistry was transformed after hearing a seminar by an English scientist named Maurice Wilkins on the DNA molecule, for which Watson had already acquired a deep interest. Wilkins, along with Watson and Francis Crick, would go on to receive the Nobel Prize in 1962 for their discovery (Watson 1968). It is clear that a driving force behind Watson's persistent pursuit of DNA, which was filled with as many if not more setbacks than successes, was its inherent importance in, as Crick would characterize it, discovering the "secret of life."

It is useful to distinguish between two types of innovation: incremental innovation and disruptive innovation. An incremental innovation is one that improves upon existing techniques in some fashion, i.e., to "build a better mouse trap." The vast majority of research innovations fall into this category. Such innovations are important, and are often necessary to make an idea practical, useful, or to overcome some other shortcoming or deficiency.

The term disruptive innovation, or disruptive technology, was coined in (Bower and Christensen 1995) and popularized in subsequent books (Christensen 1997; Christensen 2003). Briefly, a disruptive innovation is an entirely new approach or technology different from the way things are currently done. For example, in the computing industry, the mini-computer was a disruptive technology that helped to lead to the demise of many manufacturers of large mainframe machines. The microprocessor was another disruptive technology that eliminated mini-computers. Christensen provides an excellent discussion and numerous examples of disruptive technologies, and discusses their implications in business, and specifically, why existing companies have difficulty in adapting to disruptive innovations. While incremental innovations are characterized as being "sustaining" or "evolutionary," disruptive innovations are characterized as "transformational" and "revolutionary."

The processes for creating disruptive and incremental innovations are different. When developing products, incremental innovations result from customer surveys and evaluating competing products to find new ways to improve an existing product. Such practices, by themselves, do not necessarily lead to disruptive innovations. Henry Ford once remarked about marketing research "If I had asked my customers what they wanted, they would have said a faster horse." This is not to say one should not talk to one's customers, but only to point out that ideas for major disruptive changes in a field usually do not result from such conversations. In research, it is sometimes useful not to study the related work, at least not initially, to allow one the opportunity to approach a problem with a fresh mind, unencumbered with the 


\section{Fujimoto}

knowledge of approaches that have already been pursued by others. Once you have identified a problem, check out the related work only after you have taken a crack at solving it yourself.

In research, one can have a successful career developing incremental innovations, but to be really successful to propel one to the highest level in one's field, disruptive innovations can provide a fast track to success. A disruptive innovation can come about in many different ways. It can result from simply a new way of viewing a problem, or applying a new approach. Often the new approach can result from transplanting ideas and concepts from another discipline or field, as was discussed earlier. Another approach is suggested next.

\section{Suggestion 8: Define the problem, not just the solution.}

One of the best ways to become a well recognized research leader is to define key problems in the field. Being the first to define the problem positions one's self for defining the seminal work in the field. In some cases, it can result in the creation of a new field or discipline. For example, in my own field of parallel discrete event simulation, independently Chandy and Misra (Chandy and Misra 1978) and Bryant (Bryant 1977) succinctly defined the synchronization problem associated with executing discrete event simulation programs on a parallel computer. Although Chandy and Misra did only a limited amount of work, and Bryant almost none, in the field beyond their initial innovations, their names remain indelibly linked with spawning this field of research.

Interdisciplinary research areas often create fertile ground for disruptive research innovation. In the 1970 's, the parallel discrete event simulation field was spawned in the then empty white space that existed between parallel computing and discrete event simulation. Today, with the great emphasis on interdisciplinary research and the development of many new areas that did not exist twenty years ago, opportunities for innovation between disciplines are greater than ever.

\section{Suggestion 9: Develop your communication skills.}

While there is no substitute for technical innovation and excellence, one's ability to communicate can be equally important. The first step in achieving clarity in communications is to achieve clarity of thought. This in itself will do much to foster innovation. Distill ideas down to their core. Have a clear understanding of the innovative aspects of your ideas and their relationship to existing knowledge and prior work. Being able to clearly articulate the importance and ramifications of your ideas is essential to convince the research community of the importance of your results. Further, writing the key survey paper or later in one's career, the definitive textbook can help boost one's career in addition to providing a valuable service to the community.

Beyond developing the message, there is much to be said about how the message is delivered. A number of excellent ideas in this regard are presented in Heath and Heath (2007). Briefly, a few key principles are to keep the message simple, and use concrete examples. Stories and unexpected elements that can be incorporated into the narrative can create memorable messages. While not all of the techniques advocated in this reference are applicable to technical papers, many of these concepts can be incorporated into presentations and other verbal exchanges.

\section{Suggestion 10: Periodically reinvent yourself.}

"The great tragedy of age is overspecialization" (Selye 1964). Over time, researchers, especially successful ones, are prone to become more and more specialized in a narrow field of research. The "system" conspires against researchers to do this. As researchers grow and become more established, they become saddled with administrative tasks for their projects, organizational duties on conferences, paper and proposal reviews, invited presentations, press releases, etc. All of these interrupt one from creative thought 


\section{Fujimoto}

and innovation, the very things that brought one success in the first place. One must ensure that one has the opportunity to break out of this pattern if one is to maintain an innovative profile.

The sabbatical is a valuable means for academic researchers to take a year away from their position, typically in another university or laboratory, and step back, and refocus their thought and efforts to start in a new direction. Those who reside at institutions or are in circumstances that do not allow one to easily take time off in this fashion can achieve the same effect by carving off some time to devote to some new pursuit. Policies such as Google's $20 \%$ rule, mentioned earlier, provide an obvious opportunity to explore such pursuits on a somewhat more modest scale.

\section{CONCLUDING REMARKS}

Innovation and research go hand-in-hand. While one's development in technical subjects is critically important to developing a successful research career, equally important is to adopt practices that will help foster innovation. The intent of this article is to highlight these issues as aspects one should consider in developing a career in research.

As stated earlier, there are no cookbook answers that will lead to the development of great innovations. One cannot completely discount the role that luck plays. Nevertheless, innovation is not simply a magical quantity completely outside one's control. A basic understanding of innovation and how innovation has come about in the past sheds some light on how one might structure one's career to increase the possibility of developing and sustaining innovative practices. It is my hope that this article might encourage researchers to explicitly consider innovation as central to their success, study this topic further, and ultimately devise ways to become more successful innovators.

\section{ACKNOWLEDGMENTS}

This article is largely based on several books that are included in the references, all of which I highly recommend for deeper exploration. These references are all written for the popular press, and are easily accessible with no prior knowledge or background in the subject matter. Steven Johnson's Where Good Ideas Come From: The Natural History of Innovation provides an outstanding discussion of innovation and an excellent introduction to the adjacent possible as a means to explain how innovation comes about. Tom Kelley's book (with Jonathan Littman) The Ten Faces of Innovation discusses a number of strategies successfully employed by his company IDEO that specializes in innovative design. The Art of Innovation by the same author is also an excellent introduction to innovation and product design, and helped to shaped my thinking in this area. The Innovator's Dilemma is required reading for anyone in technical fields. It conveys important concepts explaining the development of technological innovation. Finally, I highly recommend Made to Stick as a reference to better understand how to deliver messages that will be remembered by your audience.

\section{REFERENCES}

Bower, J. L., and C. M. Christensen 1995. "Disruptive Technologies: Catching the Wave." Harvard Business Review 73(1, January-February):45-53.

Bryant, R. E. 1977. "Simulation of packet communications architecture computer systems." MIT-LCS-TR188.

Chandy, K. M., and J. Misra. 1978. "Distributed Simulation: A Case Study in Design and Verification of Distributed Programs." IEEE Transactions on Software Engineering SE-5(5): 440-452.

Christensen, C. M. 1997. The Innovator's Dilemma: When New Technologies Cause Great Firms to Fail. New York: Harper Business Essentials.

Christensen, C. M. 2003. The Innovator's Solution: Creating and Sustaining Successful Growth. New York: Harvard Business Press.

Eves, H. W. 1972. Mathematical Circles. Boston: Prindle Weber Schmidt. 
Glider, G. 1989. Microcosm: The Quantum Revolution in Economics and Technology. New York: Simon \& Schuster Inc.

Heath, C., and D. Heath. 2007. Made To Stick: Why Some Ideas Survive and Others Die. New York: Random House.

Johnson, S. 2010. Where Good Ideas Come From: the Natural History of Innovation. London: Penguin Books Ltd.

Kelley, T., and J. Littman 2005. The Ten Faces of Innovation: IDEO's Strategies for Beating the Devil's Advocate and Driving Creativity Throughout Your Organization. New York: Doubleday.

Kelly, T., and J. Littman 2001. The Art of Innovation: Lessons in Creativity from IDEO, America's Leading Design Firm. New York: Doubleday.

Lafley, A. G., and R. Charan 2008. The Game-Changer: How You can Drive Revenue and Profit Growth with Innovation. New York: Crown Business.

Morrison, W. F., and P. Kennedy 2006. Flat Flip Flies Straight!: True Origins of the Frisbee. Wethersfield, CT: Wormhole Publishers.

Obama, B. 2011, January 25. U.S. State of Union Address. Washington D.C. Accessed July 1. http://www.whitehouse.gov/the-press-office/2011/01/25/remarks-president-state-union-address.

Poincaré, H. 1913. The Foundations of Science. New York and Garrison, N.Y.: The Science Press.

Selye, H. 1964. From Dreams to Discovery: On Being a Scientist. New York: McGraw-Hill.

TED: Ideas Worth Spreading. 2011. Accessed July 1. http://www.ted.com.

Watson, J. D. 1968. The Double Helix: A Personal Account of the Discovery of the Structure of DNA. New York: Simon and Schuster.

World Flying Disc Federation. 2011. Accessed July 1. http://www.wfdf.org/.

\section{AUTHOR BIOGRAPHY}

RICHARD FUJIMOTO is Regents' Professor and founding Chair of the School of Computational Science and Engineering at the Georgia Institute of Technology. He is also the interim director of the Institute for Data and High Performance Computing at Georgia Tech. He received the Ph.D. and M.S. degrees from the University of California (Berkeley) in 1980 and 1983 (Computer Science and Electrical Engineering) and B.S. degrees from the University of Illinois (Urbana) in 1977 and 1978 (Computer Science and Computer Engineering). He has been an active researcher in the parallel and distributed simulation community since 1985. He led the definition of the time management services for the High Level Architecture (IEEE Standard 1516). Fujimoto has previously served as Co-Editor-in-chief of the journal Simulation: Transactions of the Society for Modeling and Simulation International as well as a founding area editor for the ACM Transactions on Modeling and Computer Simulation journal. He has also served on the organizing committees for several leading conferences in the parallel and distributed simulation field. His email address is fujimoto@cc.gatech.edu. 